\title{
Interaction Management in Nigerian Television Talk Shows
}

\author{
Professor Albert Lekan Oyeleye \\ Department of English, University of Ibadan, Nigeria \\ Tel: 234-803-473-0041_E-mail: oyeleye1@yahoo.com
}

Omolara Grace Olutayo, Ph.d

Department of Mass Communication and Media Technology

Lead City University, Ibadan, Nigeria

Tel: 234-803-637-1675Ｅ-mail: graceolutayo@yahoo.com

$\begin{array}{lc}\text { Received: July 20, } 2011 & \text { Accepted: November 15, } 2011 \quad \text { Published: February 1, } 2012 \\ \text { doi:10.5539/ijel.v2n1p149 } & \text { URL: http://dx.doi.org/10.5539/ijel.v2n1p149 }\end{array}$

\begin{abstract}
Although there is a growing number of works on discourse analysis in Nigeria which covers classroom interactions, courtroom discourse, medical communication and media discourse, the language of television (TV) talk shows has not been fully explored. This study therefore, examined turn management in this genre. It identified the turn distribution strategies in Nigerian television talk shows and the contributions of these strategies to the management of the talks. Sacks, Schegloff and Jefferson's Conversation Analysis served as our theoretical framework. Three Nigerian TV talk shows, namely, "Patito's Gang", "New Dawn with Funmi Iyanda" and "Inside Out" were selected for this study. Each selected talk show comprised four sampled episodes. "Patito's Gang" from a private television station; "New Dawn with Funmi Iyanda" from a national television station and "Inside Out" from a private television station were purposively selected because they were handled by freelance presenters who were free from undue interference. Collection of data spanned four years: 2004-2008. And the analysis was both quantitative and qualitative. Generally, three turn distribution strategies were identified: Current-Speaker-Selects-Next-Speaker, Next-Speaker-Self-Selects-as-Next and Current-Speaker-Continues (where there is no pre-selection or self-selection). Current speaker selected next speaker by direct questioning, gaze and gestures. Next speaker self-selected as next through interruptions, overlaps, discourse markers, pauses and falling intonation. Where there was no pre-selection or self-selection at Transition Relevance Places, the current speaker continued after a pause of about half a second or more. These strategies enabled effective interaction management amongst the participants as turn allocation was not restricted but moderated by the hosts.
\end{abstract}

Keywords: Interaction, Turn distribution strategies, Television talk shows, Conversation analysis, Turn allocation, Transition relevance place

\section{Introduction}

\subsection{Definition and characteristics of Talk show}

Like the soap opera, the talk show is an invention of twentieth century broadcasting. It takes a very old form of communication, conversation, and transforms it into a low cost but highly popular form of information and entertainment through the institutions, practices and technologies of television (peerpapers, 2010). A talk show is a television or radio program where one person (or group of people) discusses various topics put forth by a talk show host. Sometimes, talk shows feature a panel of guests, usually consisting of a group of people who are learned or who have great experience in relation to whatever issue is being discussed on the show for that episode. At other times, a single guest discusses his work or area of expertise with a host or co-hosts (Wikipedia, 2009). Television talk shows often feature celebrity guests who talk about their work and personal lives as well as their latest films, TV shows, music recordings or other projects they would like to promote to the public. The shows selected for this study, however, dwell on topical, moral, economic and social-political issues as they affect Nigerians. Talk shows are indeed forums through which society comes to terms with the topics, issues and 
themes that define its basic values, what it means to be a 'citizen', a participating member of that society. Several TV talk shows in Nigeria such as "Patito's Gang", "Tuesday Live on NTA", "New Dawn"and "Inside Out" have become microcosms of society as cutting-edge social and cultural issues are debated and discussed.

\subsection{Types of talk show}

According to most veteran broadcasters, there are two types of chatter on TV. The first is "television talk," defined by the Museum of Broadcast Communications as unscripted conversation directed to the audience, and "talk shows"--shows organized principally around talk. "Television talk" represents all the unscripted forms of conversation and direct address to the audience that have been present on television from the beginning. This kind of "live," unscripted talk is one of the basic things that distinguish television from film, photography, and the record and book industries. However, as the genre continues to expand, it has not been easy to draw a clear line between "television talk" and what formally constitutes a talk show.

Wilson (2008:3) classified talk shows into three main types namely: tabloid shows, late night shows and daytime talk shows. Tabloid talk shows are a type of talk show which achieved maximum viewers in America, during the late 20th century, airing typically during the day. This type of show started with the Phil Donahue show in 1967 and was made very popular by the Oprah Winfrey show. The host invites a collection of guests to talk about an emotional or provocative topic, such as infidelity, or a daughter trying to find her mother after twenty years. And the guests are encouraged, more often than not, to make confessions and determine their problems with on-camera "group therapy". The daytime and late night shows often follow the same format which includes: a standup comedy segment called the monologue, where the host makes jokes about current events, several skits or other comedy bits (AllFreeEssays, 2010).

There are several types of talk shows but there are two most common formats namely: the informal guest-host format, in which the show's host welcomes celebrities or other talk-worthy individuals in what is perceived as an informal discussion. "Tuesday Live on NTA" anchored by Cyril Stober, "Today's Woman" anchored by Adesuwa Onyenokwe, "Prime Woman" on Gateway Television and some others will fall into this category. The second most common format is the public affairs show, in which a host (or hosts) interviews people in the news or experts in a given field. Shows that follow this format include both the morning news programmes and "issue" talk shows. Our selected talk shows: "Patito's Gang" (PG), "New Dawn with Funmi Iyanda" (ND) and "Inside Out with Agatha" (IO) follow this format.

There are no rules that talk shows follow but the Museum of Broadcast Communications' Bernard M. Timberg notes two governing principles of all successful talk shows:

- The host is everything: from Letterman to Degeneres, the host maintains a high degree of control over their show, from subject matter to comedic tone. They are also the brand and must carry that burden. The host can attract and repel guests, negotiate in kind for their programme and, in many cases, name a successor when they retire.

- Right here and now: the second rule is that a talk show must be experienced in the present tense, whether it is broadcast live or taped in front of an audience earlier in the day. They should feel fresh as if they are happening in the moment even if the show is a 10-year-old-rerun.

Although a lot of works have been done on T.V. talk shows outside the shores of Nigeria

(Shattuc, 1997; Fromm, 1999; Gamson, 1998; Tolson, 2001; Lunt and Stenner, 2005; Trepte, 2005; Hamo, 2006 etc.). However, the language of Nigerian television talk show has not been fully explored. Interests have been more on classroom interactions (Olateju, 1998), courtroom discourse (Onadeko, 1999), medical talks-doctor/patient interactions (Odebunmi, 2003) and print media (Chiluwa, 2005). This research work attempted to fill this gap by examining natural conversations through the broadcast media especially one that reflects the non-verbal cues in conversation. We examined the turn distribution strategies in Nigerian TV talk shows, and how these contribute to effective interaction management during the process of the conversation.

The motivating factors for this study were personal observations of the linguistic intricacies of conversations as reflected on some Nigerian television talk shows and the differences that seemed to emerge in turn-taking behaviour or interaction patterns such as pauses, overlaps and interruptions. The intent of this study is to investigate how turn taking behaviour and interaction patterns help the participants to interpret each other's meanings and intentions in the process of conversations. Our choice of television talk shows was prompted by the opportunity to watch real life conversations on the television and examine how the participants continually engage themselves in continuous interactions by holding the floor, yielding the floor and taking the floor. 
This study examined various types of turn-taking strategies adopted by participants in television talk shows. Using the theory of turn-taking, it specifically studied the strategies of turn distributions such as Current Speaker Selects Next Speaker, Next Speaker Self-Selects and Current Speaker continues where there was no pre-selection or self-selection through features like overt questioning, discourse markers, interruptions, overlaps, and pre-sequences including non-verbal signals such as gaze, gestures, intonations and pauses. It also studied the pragmatic effects of these features on the discourse and the participants.

Three popular Nigerian television talk shows made up of daytime and night shows were examined. They are: "Patito's Gang" (henceforth to be referred to as PG), "New Dawn" (ND) and "Inside Out" (IO). ND was a daytime talk show aired in the mornings on NTA Channel 10, Lagos, during the weekdays; IO was on Sunday afternoons on Gateway Television, Ogun State, while PG was a night show also aired on Gateway Television, Abeokuta, Ogun state. The decision to use the Gateway Television station and NTA channel 10 as the media outlets for this study was motivated by the fact that talk shows were prominent features of many programmes on these stations, and we were confident that the required number of talks would be found there. The three programmes chosen for this study are well-established as they have been on air for over five years. They also enjoy wide viewership because of their various interesting, current as well as thought provoking topics. Although, there were several talk shows on Nigerian television stations during this research work, the purposive sampling technique was adopted in choosing the three TV talk shows selected for this study. Coupled with this, the shows were selected because they were handled by private individuals who were not employed by the state or federal government. Thus, the hosts were free to feature any topic of their choice without restrictions; they could also invite guests who they considered suitable for their programmes. There was room for freedom of speech. These features provided us opportunities to compare and use our findings to generalize on other talk shows on the Nigerian media. For ease of analysis four episodes were selected from the arrays of episodes recorded for the purpose of this study. The episodes were also selected because they discussed topical issues which were of national interest.

\subsection{The talk show genre}

Outside the shores of Nigeria, particularly in America, talk show has been viewed as the most controversial TV genre. Many scholarly comments seem impelled to have lined up either for or against the terms of the controversy. There are about three camps in the controversy. "In the first camp there are some writers who express profound moral ambivalence or even hostility toward the talk show. These writers are then contradicted by others who seek to defend the genre, sometimes in political or more precisely sexual-political terms". In the third camp are others who are critical of the terms of this defense (Tolson, 2001:7). Writers with sociological orientations like Cohen, 1972; Nelson and Robinson, 1994; Abt and Seeholtz, 1994 Thompson, 1998, studied the effects of talk shows on the society. They opined that talk shows go against the moral values of America. They claim that:

To experience the virtual realities of television talk shows is to confront a crisis in the social construction of reality. Television talk shows create audiences by breaking cultural rules, by managed shocks, by shifting our conceptions of what is acceptable, by transforming our ideas about what is possible, by undermining the basis of cultural judgment, by redefining deviance and appropriate reactions to it, by eroding social barriers, inhibitions and cultural distinctions

(Abt and Seesholtz, 1994:171).

According to Lunt and Stenner (2005), there is now an established body of literature in media and communications on the talk show genre (Livingstone and Lunt, 1994; Shattuc, 1997; Gamson, 1998; Tolson 2001; Dovey, 2000). This literature includes the detailed analysis of interaction on talk shows and the discussion of the broader social significance of talk on television. Research into talk shows has brought out a number of issues such as realism and representation in talk shows; the balance between spontaneity in and control over interactions; the gendered dimensions of the programmes; the role of the hosts and the quality of arguments on the shows. These scholars have argued against the views that talk shows are irrelevant and meaningless 'trash television'. Instead, they posit that talk show genre emerges as a context for public participation and debate (Livingstone and Lunt, 1994) as the basis for occasions that afford the expression and exploration of emotions (Shattuc,1997), and as an opportunity for the expression of voices that are otherwise excluded from the media.

Different approaches have also been advocated for the study of talk shows. The study of talk show as a public sphere has adopted Harberma's (1989) arguments concerning the institutionalisation of the political public sphere. These empirical studies of talk shows and audience take Haberma's conception of the bourgeois public 
sphere as their starting point. From there, discussion focuses on such issues as whether talk shows are sufficiently free of institutional control; provide freedom of access and voice; and constitute a viable framework for the formation of public opinion as an emergent consensus concerning issues of the moment (Lunt and Stenner, 2005). Critics of the public sphere theory conclude that there are often no conclusions or consensus when talk shows are examined as public sphere. Instead they are characterized by fast- moving chaotic interactions which often descend into quarrels.

Apart from the reformulations of the public role of talk on television, a number of literatures have emerged on the language and interaction that occurs on talk shows. Analyses focus upon such matters as the role of the host (Tolson, 2001) and the variety of discursive markers of the different roles and phases of the shows. These studies emphasize the devices deployed in talk shows to construct the sense of liveness in the programmes (Thornborrow, 2001), to frame quasi-therapeutic interactions (Brunvatne and Tolson, 2001) and to manage conflict between experts and ordinary people (Wood, 2001). These detailed analyses of talk show demonstrate the subtle ways in which participation is constructed to draw the studio guests, the hosts, and the home audience into a participation framework (Goffman, 1981). These studies indicate that there are important differences between the way that performance and discussion are handled in different talk shows. They also identify the affinities of talk show interactions with everyday conversations, document the ways in which the shows reflect their institutional setting, and analyse how they are produced for an overhearing audience (Tolson, 2001). However, this study goes a bit further to examine the linguistic intricacies in Television talk shows which include how turns are taken and yielded.

\section{Theoretical Framework}

\subsection{Conversation Analysis}

Conversation Analysis (CA) is an outcome of an ethnomethodological tradition. Ethnomethodology is a sociological perspective, founded by the American Sociologist, Harold Garfinkel in the early 1960s to explain and understand meaning systems and procedures between people and how they make sense of their social world. CA was developed collaboratively by Sacks, Schegloff and Jefferson to study ordinary conversation in order to discover if organizational details could be formally described. The idea is that conversations are orderly, not only for observing analysts, but in the first place for participating members (Schegloff \& Sacks, 1973: 290; Sacks, 1984a: 22). The field of CA is primarily concerned with finding the organization of social action located in discursive practices in everyday interaction. The first analysis came from detailed inspection of tape recordings and transcriptions made from such recordings:

I started to work with tape-recorded conversations. Such materials had a single virtue that I could replay them. I could study it again and again, and also, consequentially, because others could look at what I had studied and make of it what they could, if, for example they wanted to disagree with me

(Sacks et al, 1974, P. 715).

The primary concern of Conversation Analysis is sequential organization, or the ways in which speakers organize their talk turn by turn (Neuliep, 1996). Unlike the deductive approach of Discourse Analysis, CA aims to reveal through inductive study, the structures of naturally occurring interaction on the basis of detailed transcripts of audio or video-recordings. CA moves away from single utterance as a focus of attention, characteristic of Speech Act Theory, and explores the sequential organization of interaction and its basis in the turn-taking system. (Bryan, 2000).

CA builds on the view of ethnomethodologists that members of a society use common-sense knowledge which is based on a background of common understanding' (Garfinkel, 1967:49) to interpret events and behaviours encountered in everyday social setting and thereby to organize their interaction on an ongoing basis. It adopts an empirical approach to the study of interaction in real-life, everyday social activities. The focus is on the individual nature of the situations studied, their uniqueness being attributable to the role played by the actors in determining how events unfold. CA attempts through extensive field study of naturally occurring interaction to learn about such activities from within and eschews the establishment of general theories, which detach interaction from the context in which it occurs.

Experimental and other laboratory-generated data favoured by social psychological research are rejected. Reliance on field notes as a record of observation, characteristic of ethnographic research is questioned due to inadequacies of memory. Thus transcribed recordings of face to face and telephone interactions constitute the basis for analysis because they permit ongoing review of the data in the light of other research questions and a means of comparison 
(Byran 2000). Thus CA is a useful analytical tool for television talk shows where there are face-to-face interactions which are useful for the observation of how the talks break into "turns" - which are sometimes reciprocally agreed to and at other times hotly contested among participants.

\section{Example 1}

1) A: What did you receive out of Nigeria? (laughter)

2) B: What's the progress?

3) $\mathrm{C}$ : The gladdening thing in all these is the fact that the issue of leadership is now an idea....

4) D: Youth and leadership. Erm... there is a number of programme... erm either just started some have been running in different ways and in the faith foundation the work you've been doing on entrepreneurship erm...

\section{"Leadership" from "Patito's Gang"}

Participants in example 5 above display a hot contest for the floor. 4 eventually had access to the floor.

One of the first studies that employed CA examined turn-taking in conversations (Sacks, Jefferson, and Schegloff, 1974). The moment in a conversation when a transition from one speaker to another is possible was called a transition relevance place (TRP). TRP's were seen as operating in all conversations and were utilized by participants as potential end of a turn. TRP's prevented chaos. Thus turn-taking is context free (e.g. turn taking occurs in all interactions) and also context sensitive to a variety of particular conversational happenings.

There are several ways that a TRP is typically accomplished (Sacks et al., 1974). A speaker can select the next speaker and either verbally or non-verbally conveys this transition prior to the TRP. In the absence of this choice, the TRP is an opportunity for any listener to take a turn through self-selection. This can be a problem when one speaker is a quick starter and another is slower to begin a turn. Also at the TRP, if there is no pre-selection and no one self-selects, then the speaker can continue. A pause of half a second or more at these TRP's could suggest avoidance of participation, misspeaking, confusion, surprise, anger, etc.

The implications of these manoeuvres are significant. As conversational turn-taking is interactionally managed, what one participant does affect what the others may acceptably do. For example, when the current speaker selects the next speaker, this often effectively rules out other listeners from self-selecting. As Nofsinger, (1991) notes:

Many of the conversational tendencies and orientations that we commonly attribute to participants' personalities or interpersonal relationships derive (at least in part) from the turn system. For example, other participants may listen to us not because they are interested or because we are fascinating, but because they have to. (P. 89).

According to Levinson, (1983: 298) the techniques for selecting next speakers can be elaborate, they include straightforward devices as - a question (offer, or request etc) an address term; a tagged assertion plus an address feature and the various hearing and understanding checks (Who? You did what? Pardon? You mean tomorrow? etc.). This selects prior speaker as next.

\section{Example 2}

1. Host: Just moving forward from who.. who ...erm a leader is and how we define a leader(.) I will like for us to focus on efforts that are being made to create in a way of models of leadership and and I know that FEP has been doing em... fantastic job. I have seen some of erm... newsletters and talks (.) Perhaps, you can bring us up to book on some of the works you have been doing erm... in Benson Idahosa University, a project that you are running (.3) you were in Abuja not long ago and all of that. What what's the goal and how are you walking at it? And how is it coming along?

2. Participant: Ah... thank you very much (.) Theirs is bound(sic) line in what we are trying to say as a matter of fact(.) how is it going? Et cetera. I think many of us so many so many times try to focus on what is the wrong kind of leadership and what is the right kind of leadership...

The host (the current speaker) in Turn 1 above, combines about three strategies to select the next speaker. The strategies are gaze, request and question. It was the participant whom the question, gaze and request referred to that took the turn as no name was mentioned by the host. 


\section{Method of data analysis}

The quantitative and qualitative method of analysis was adopted for this study. Using the frequency count and simple percentage, the strategy that had the highest percentage was identified and the implication was also discussed. The qualitative analysis was carried out with the intention of examining selection of next speakers and the pragmatic effects of the turn distribution strategies on the discourse, hosts, participants and even the viewers of Nigerian TV talk shows. Based on Sack, Schegloff and Jefferson's turn-taking model, the allocation of turns in the current study is defined by a set of rules as follows:

1. If the current speaker chooses to use a Current Speaker Selects Next (CSSN) technique, then the chosen party has the right and is obliged to take the next turn to speak while the other interlocutors are quiet. An example of CSSN technique is as follows:

\section{Example 3}

Host:

I just want to..., I want to get another view, because if we start the discussion now it won't end. Dr. Leke Pitan, I..., I..., I want to... if you would like to add anything to that.

Participant1: Haa... yes, haa... apart from those who eeh (.) who have the Person (sic) he has just described are those they say have learning difficulties that is the terminology we use now but beyond that we also have those who are visually impaired...

Host: that like the blind (sic)

Participant 1: no we don't use that terminology]

\section{Inclusive Education from "Inside Out"}

2. If the current speaker does not use the CSSN technique, self-selection is instituted. In this study, self-selection is illustrated when the host wants to solicit ideas from participants without referring to anyone in particular; thus the floor is taken by the first speaker to take the floor or in case they are more than one, the one who succeeds probably through a louder or a more forceful voice gets the turn. One example of this technique follows:

\section{Example 4}

Host:

Are you saying... Wait. Are you saying... because if I should go by what you have just said \{many overlapping statements\}

Participant3: (Female) what is obtainable in the world... he doesn't know all the women in the world, he doesn't know me and I don't know him okay...

Host: $\quad$ if... if what you have said is the truth(.) what it would mean is that majority of women based on what..., the, the perception in the society today are thinkers and not feelers but I don't think that is true.

Participant 1: Neither do I say that, we have a lot of women in the world today that are feelers but am saying that it's not, when we are talking what we are trying to say is about the fact that hem, hem Glory was saying something Tony was trying to discount it but I am trying to say what Glory was saying is really true, she, she's not saying something outside of who she is......

Self-selection could also occur after a current speaker chosen through a CSSN technique has presented his or her ideas; the third party who thinks he has a related idea may take the turn. This technique is illustrated below:

\section{Example 5}

Host: $\quad$ Alright... what I'm trying to lay... because... you know... emphasis on is that, you said, it is not a poor or rich people's problem but some people argued that for example people live in FACE ME I FACE YOU but they get urban slum how is going to plant tree in a house of about forty people you know? How do we, how do we make this workable thing in an environment with the challenges of our environment?

Mr. D: $\quad$ I think they need to know what it means by conservation of planting trees; that is a first challenge. Telling somebody who is trying to look for food to plant trees is very challenging and that is what 
Mr. A: $\quad$ I also feel that we have been looking at global role or we've been looking international role and we've been looking national role, there is what we call community or neighborhood would want to look at the need for such facilities around their homes even, if they live in FACE ME I FACE YOU, there are open gate opportunities in some situations which you can improve and call that place and the issue of ... generated in a hoodlum around the community provide you with something and also change the mentality that children need to be born in a place where they don't see trees for years until they attain twelve years and they are taking to a small forest they don't believe that they are still in the world. It's not ....

3. If no participant self-selected after a pause, the current speaker continues with his contribution. This technique is referred to in this study, as CSC. An example is illustrated below:

\section{Example 6}

Participant2: hem... they are obsolete. They sort of the number of this gang who is used to being part of the decision making process to bring in (laughter)

Participant2: I was talking about hem could it be that hem have we've it has not got leadership in that other specialists you know hem due to be ah I'm being very careful with the choice of word and you know the medical doctor all time seems to be driver, the pilot and every other specialist is subsumed under his control. So when the decision now comes in choosing the right equipment, obviously, it depends on the way the manager, in quote sees it rather than getting the specialist at the day and say listen let get this down... "Radiology and Healthcare" in Patito's Gang

\section{Analysis of Data}

The episodes selected from our samples are stated below:

From "Patito's Gang" (PG):

"Declaration of State of Emergency in Plateau State." - PG1

"Radiology and its Role in Healthcare Maintenance." - PG2

"Physical Challenges" - PG3

"Abuja." - PG4

From "New Dawn, with Funmi Iyanda" (ND):

"Global Warming"-ND1

"Fan's mails"-ND2

"Change a life." -ND3

"Wole Soyinka"-ND4

And from "Inside Out" (IO) we have:

"How safe are we?" -IO1

"Inclusive Education."-IO2

"Show us our place."- IO3

"No romance without Finance." -IO4

\subsection{Quantitative Analysis}

Table 1 summarises the frequency of the three turn distribution strategies in Patito's Gang. The result shows that there were 48 instances of CSSN in PG1, 19 in PG2, 15 in PG3 and 14 in PG4. From the four episodes, CSSN = $15.9 \%$, NSSS $=64.6 \%$ and CSC $=19.4 \%$. Total percentage of turn distribution strategies $=99.9 \%$. It is therefore obvious that NSSS was the most dominant strategy adopted in this show; it has the highest percentage out of the three turn distribution strategies identified in each show. PG1 had the highest number of occurrence because of the nature of the topic at that time. It was a controversial topic; one that touched every Nigerian. Thus every participant sought an opportunity to participate in the talk. The high rate of NSSS in PG also suggests high involvement of the participants in all the episodes.

Table 2 reports the turn distribution strategies in ND. CSSN $=26.7 \%$; NSSS $=51.5 \%$ and $\mathrm{CSC}=21.7 \%$. Total percentage of turn distribution strategies $=99.9 \%$. The percentage of NSSS in ND2 is the highest of the four. This suggests that participants enjoyed more access to the floor in this episode than in the others. The entire 
results indicate that there were fewer instances of NSSS in ND than in PG. The decrease in the number of NSSS demonstrates that turns were not evenly distributed in ND and that participants were restricted to taking the floor only when the host selected them. CSSN follows closely with $26.7 \%$. This indicates that while the host had the upper hand, the participants still found a way to be involved in the discussion.

In Table 3, the numbers of the turn distribution strategies identified are quite lower than what we have in the first two tables. This is mainly due to the duration of the show. IO was a 30 minutes show; so there was no room for many turns. The frequency of occurrence of NSSS is also higher by $57.5 \%$ than that of CSSN and CSC. This demonstrates the liberal nature of the host and her desire for interaction. The nature of the topics also called for a higher level of participation from the interlocutors.

Looking closely at the tables above, NSSS had the highest percentage in IO1, while CSSN and NSSS share the same percentage in IO2. This indicates that IO1 was more interactive than IO2. The similarity in CSSN and NSSS in IO2 is a reflection of the topic; "Inclusive Education" (IO2) was not as controversial as "How safe are We?" (IO1). IO2 was also an enlightenment programme meant to sensitise the viewers to include the physically challenged in normal education. IO4 had the highest percentage of NSSS. The topic of this episode ("No Romance without Finance") called for more audience participation. The nature of the topic always determines the rate of occurrence of turn distributions

Therefore, we can safely conclude that the frequency of turn distribution is similar in the three (3) shows, even though the quantity is different. Out of the three turn distribution strategies, NSSS was the most selected.

\subsection{Qualitative Analysis}

\subsubsection{Current-Speaker-Selects Next (CSSN)}

CSSN occurred mostly at the beginning of the shows, especially where the hosts introduced the guests, through direct questioning, gaze and gestures. Instances of these occurrences are presented below one after the other:

\section{Excerpt 1-PG3}

1. TH: We are back. This is Patito's gang. Today, a really important subject matter; we are looking at physical challenges. Handicaps that many of our citizens are challenged by they can be handicaps in term of visual impairment, in terms of hearing, in terms of the ability to speak, or they can be physical handicaps in terms of well bone structure and all of that. Many, many of our citizens have to live with these challenges. In many parts of the world a special attention paid. In fact, public politics requires a response to these handicaps to allow these people more complete lives. But here we've not even started. Today, we're going to look at physical challenges and how people are coping with them, what can be done to make their lives fuller. And I've got the gang with me and they are going to put their heart to this matter that really does touch the heart. And I've got from my left:

2. PP1: Michael Aderounmu,

3. PP2: Reuben Abati,

4. PP3: Njide Kanedike,

5. PP4: Cordelia Chinwoke

From the excerpt above, the host employed CSSN so that the participants could introduce themselves to the viewers. This was accomplished through gaze; the host gazed at each participant and without having to say anything and the next speaker takes his turn. Only on very rare occasions as we have in the excerpt below did the host as the current speaker selected the next speaker at the beginning of the conversation in PG.

There were also a lot of instances of CSSN through gaze and gestures in ND and IO. ND being an interview format had a lot of instances of CSSN. Oftentimes, the host called the next speaker by name and gazed at $\mathrm{him} / \mathrm{her}$ to signal that it was his turn to take the floor as shown in the excerpt below:

\section{Excerpt 2-ND1}

56. TH:

57. PP1:
Mr. Adeleke what do you make of this. I didn't know that there was such a possibility .......

I know that people do have different beliefs, I know some people who worship rivers, there is Olokun, there's Yemoja but these are traditional beliefs. In those days, people who lived very close to that place believe that the beach have a kind of spirit because it is cool and it has its own aura, because of the comfort; you may have something 
towards it and it is also a way of appreciating God and people think there should be something special there. I am not saying there are not all such things don't happen but what we are saying is that climatic conditions do change and the changes have been affected in last fifty years...

In this excerpt, TH turns to gaze at Mr. Adeleke indicating that he should take the floor. She also engaged in pointing at the next speaker:

\section{Excerpt 3-ND1}

TH:

S. A:

Otherwise nature will find a way anyway o.k. who's next? \{Points to the next person\} eh... sir, I just want to make a contribution in this part of, of the world, in Nigeria most especially, you see people are after money, now if you tell them to create a portion at the back of their house to plant trees and some thing there, they will look at it, what they will, what will that one give me. Will that one .... Or if I should go there and construct two chalets there what will that one give me? It's an individual thing that we should eh eh imbibe into ourselves money is not about everything you see, you said I, I for example you said if I live in a face me I face you. You want me to plant, what about? What will the landlord say? And if I suggest that to the landlord will the landlord will tell me that I prefer to build two rooms

there than planting, than planting one kind of tree that at the end of the day it will go and go with life

\subsubsection{CSSN through direct questioning:}

\section{Excerpt 4-IO3}

10. TH: Ferdinand, let me talk to you, you represent GOTNI what does that mean?

11. PP3: it is an acronym for Guidance of the Nation International

12. TH: okay what do you do?

13. PP3: okay we are leadership organization

In this excerpt, no other participant had the right to take the turn as the question was directed at Ferdinand. Other interlocutors had to wait until there was a convenient time to take the floor. This indicates that the choice of TH is respected; it also reflects control as regards the authority of TH to allocate turns.

\subsubsection{Next-Speaker-Self-Selects- as Next (NSSS)}

This is a major strategy adopted in the talk shows examined in this study; especially, in shows presented by liberal hosts and ones with controversial topics. NSSS occurred through questioning, interruptions, overlaps, discourse markers, after a pause, and after a falling intonation.

\subsubsection{NSSS through questioning}

NSSS could occur through questioning in a talk show with more than one guest, the type we have referred to in this work as a multi-party talk. For example, when the host throws a question to the floor and that question is not directed at a particular guest, any of the

participants who thinks he has an answer to the question may self-select as we have in the excerpt below:

\section{Excerpt 5-PG1}

3. TH: Now, how did we get to the state of emergency? What really come to cause this situation?

4. PP2: $\quad$ Em... let me start by describing that em by saying that em there was nothing, absolutely nothing that called for a state of emergency in Plateau state. Secondly, that the propriety of the action is fundamentally flawed and questioned. Thirdly, that the legal regime in terms of our constitution expectation does not permit what Mr. President had done. It's an irony of life that while South Africa is busy celebrating her hosting right of 2010 World Cup, Nigeria was busy declaring a state of emergency. It's an irony of life(.) that while some countries, are celebrating their gains of democratic gains life free and fair election in South Africa, Nigeria is coming out with new petroleum fuel prices. Now, what is the legal framework under which Mr. President can declare a state of emergency. It's to be found in Section 3045 of the Constitution of the Federal Republic of Nigeria 1999, which says that whenever Nigeria is in a state of war or there is an invasion of 
the country or there is a total breakdown of law and order, or clear and present of a total breakdown of law and elder I mean order, then Mr. President can.

\subsubsection{NSSS through interruptions}

Participants and even the hosts engaged in NSSS through interruptions. This often occurred when a participant felt he/she had a contribution to make contrary to or in support of the current speaker. The hosts self-selected as the discussion got hotter and he/she decided to make his/her contribution. At other times, it may be as a result of a commercial break or in an attempt to change the trend of the conversation.

\section{Excerpt 6-IO3}

14. TH: Actually, actually we did something on that, what is the value of human lives?

15. PP1: Absolutely, so until a critical mass just like young people would say this where am going to watch this and say yes we can, we can make a different from our school communities you know from our family way we can make a difference \{applause\}.

16. TH: let me take a break, when we come back I want to talk about, I want to let us know your view about why you think this is based on what you do now? Why is here a faulty leadership? And why you think this is necessary about what you are doing? Let's take a break we will be back.

In the excerpt above, TH employed NSSS to call for a break and redirect the discussion.

\subsubsection{NSSS through overlaps}

Sometimes, when participants attempt to self-select, many overlapping statements may be recorded as we have in the excerpt below:

\section{Excerpt 7-IO4}

8. PP2: what you have said is very fundamental that the guy is rich but not romantic. Romance, as far as am concerned... you have to be creative, it can be small things, writing a letter, not many people will think about that in this their age, the girl might come to your house

9. $\quad$ to see you and you have already written the letter and she sees it and reads it and you see it then it didn't cost anything ]

10. PP1: [it costs something..........

11. PP2: it costs a lot of things (many overlapping statements)

4.2.2.4 NSSS through discourse markers

Participants often employ discourse markers which are also known as preliminaries to self-select. These discourse markers show that they were not selected to take the floor, they are only used as pre-sequences to get the approval of the current speaker to take the floor as we have in the excerpt below:

\section{Excerpt 8-PG2}

PP1: You know what, you know what. My fear is that we have a situation where the head of institution don't have the autonomy over their funds or funding properly

PP3: I don't know how such is going to...

TH: If like... you said... you want to have... you want to take the conditionalities (sic) I mean if you have a situation where they let's take the hem the education trust fund. It's going to provide assistance to say five universities; you don't even know that, that assistance is coming. Next time you got a letter that say look you know we always thought we should help you; we have this consignment of hem...

\subsubsection{NSSS after a pause}

NSSS could also occur after a pause, the next speaker may take the opportunity of a pause of about a second to self select. In the excerpt below, TH self-selected after a pause of about a second to seek clarification. This type of NSSS does not always last long, that is the length of the turn is usually short because the last speaker often regains the floor in time.

\section{Excerpt 9-IO1}

31. PP1:

...When I insisted on the identification you know what he did, he kept driving off and I ran after him then I realize someone called me from this Agatha programme and said do I realize 
that today is this programme? I said no, let me leave this guy. Ironically, the guy was shivering, I don't want to digress what am telling you is this you see (.)

32. TH: could it be he is not a policeman

33. PP1: he's not ...he's not, when I said that because the moment I said that I was like ha... make I just quickly run comot, he be like say this one no be normal person o(laughs and murmurs)

4.2.2.6 NSSS after falling intonation

NSSS also occurred after falling intonation. In this instance, the next speaker assumed that the current speaker had completed his contribution; he took the floor when he noticed a fall in the current speaker's voice.

\section{Excerpt 10-IO1}

17. PP1: $\quad$ You see why I said the country is safe is this, this time my friend came in here with this telephone he was not dispossessed of it (?) certain things have happened in the past one month or there about that some people who came \{muddled words\}not in Lagos anyway those do not indicate that we are in an unsafe

environment(.) if we are not safe we cannot be here(.) I cannot come in here in uniform in my brand new 306 and am putting on this in UNILAG those in my alma mater and if there is no safety that is one thing you have to take note of. We have a re - occurrence (sic) situation in crime just at a time you might have money on you and a time you don't have you say oh am broke

18. TH: So there trying period

\subsubsection{Current-Speaker-Continues (CSC)}

Current speaker in TV talk shows may continue speaking where there are no pre-selections or self-selections. In this study, CSC occurred after a pause of about one or three seconds and after backchannels.

\section{Excerpt 11-PG2}

PP2: I was talking about hem could it be that hem have we've it has not got leadership in that other specialists you know hem due to be ah I'm being very careful with the choice of word and you know the medical doctor all time seems to be driver, the pilot and every other specialist is subsumed under his control (.) So when the decision now comes in choosing the right equipment, obviously, it depends on the way the manager, in quote sees it rather than getting the specialist at the day and say listen let get this down (sic). Could it also be that due process is not followed? If due process were to be followed, which result, what again this issue of corruption, you know, otherwise you want to buy a piece of equipment, the people who are the specialists who are going to use it and have a tendency of being up to date in the knowledge of the equipment rather than somebody being there and tell you listen, we'll get the contractor, let him supply this equipment and someone just come from nowhere who will present different kinds of equipment (.)

therefore, questions I'm asking could it be the issue of the leader of the team, okay, that at all time must be a medical doctor and other specialists must be second...

Sometimes CSC occurred after backchannels. Backchannels are employed by the host or other participants to indicate their active involvement in the discussion. The backchannels could be verbal or non-verbal (applause or laughter).

\section{Excerpt 12-ND4}

1. PP: Well you know, memory is an interesting thing. Em... em... you can forget what happened yesterday and remember with absolute clarity what happened so many years before. It... it varies; the mind is very selective, memory is a selective mechanism, things which you just don't want to deep down you don't want to remember, you forget almost immediately it happened you ask oh! What is it that, what exactly, what was it I was saying just now? Don't you all do that from time to time?

2. TH \& others: oh yes (back channel) 
PP: The same applies to these months, years at times, perhaps I can recall with absolutely clarity it's like what was, was doing the day Sanni Abacha died. I received a call and I can describe every micro second bit of what happened that day with absolute clarity. So that's way it goes.

In the excerpt above, TH and others acknowledge the contribution of PP through a backchannel- oh yes but PP continued his turn after the backchannel. This indicates that PP had not finished his contribution.

In Turns 41, 42, 45, 47 and 49, there were backchannels; however they did not disturb PP1 from completing his turn. This suggests that a speaker who has not finished his contribution will not be deterred by the responses of other participants and the studio audience; he could hold the floor until he has completed his turn.

\section{Conclusions}

The foregoing analysis and discussions of turn distribution strategies provide an insight into Nigerian television talk shows with their unique ways of presenting issues to viewers.

The analysis has also shown that NSSS is the most dominant strategy adopted in Nigerian television talk shows and the qualitative analysis indicate that there is always a shared understanding amongst the participants as regards who takes the floor, when a speaker should yield the floor, how a speaker would know that another speaker wishes to take the floor. The data has shown that Nigerian TV talk shows have a format comprising opening/introduction, body and closing/conclusion; the three parts are effectively managed through successful turn- taking.

\section{References}

Abrahams, Roger D. (1983). Man-of-Words in the West Indies. Baltimore: John Hopkings University Press.

Brunvatne, R. \& Tolson, A. (2001). It Makes It Okay to Cry": Two Types of "Therapy Talk in TV Talk Shows". In A. Tolson, (Ed.) Television Talk Shows: Discourse, Performance, Spectacle. Mahwah, NJ: Lawrence Erlbaum, 139-154.

Chiluwa, I.E. (2005). Discourse Pragmatics of News Headlines and Lead Stories in Tell, The News and Newswatch. Ph.D Thesis, Department of English, University of Ibadan, Ibadan.

Cohen, S. (1972). Folk devils and moral panics. London: MacGibbon \& Kee.

Dovey, J. (2000). Freakshows: First-person Media and Factual Television. London: Pluto Press.

Fromm, B. (1999). Privatgesprache vor Millionen. Fernsehauftritte aus psychologischer und soziologischer Perspektive [Private talk: A psychological and sociological perspective on lay participation]. Konstanz, Germany: UVK Medien.

Gamson, J. (1998). Freaks Talk Back: Tabloid Talk Shows and Sexual Non-conformity. Chicago: University of Chicago Press.

Garfinkel, H. (1967). Studies in Ethnomethodology. Englewood Cliffs, NJ: Prentice Hall.

Goffman, J. (1981). Forms of Talk. Pennsylvania: University of Pennsylvania Press.

Harbemas, J. (1989). The Structural Transformation of the Public Sphere. Cambridge, MA: MIT Press.

Levinson, S. (1983). Pragmatics. Cambridge: Cambridge University Press.

Livingstone, S. \& Lunt, P. (1994). Talk on television: Audience participation and public debate. London: Routledge.

Lunt, P. \& Stenner, P. (2005). The Jerry Springer Show as an emotional public sphere. Media, Culture \& Society. Vol. 27(1): 59-81. Communications Library-Fax. [Online] Available: http://mcs.sagepub.com (August 14, 2007)

Nelson, E. \& Robinson, E. (1994). Reality talk or telling tales? The social construction of sexual and gender deviance on a television talk show. Journal of Contemporary Ethnography, 23(1): 51-78. http://dx.doi.org/10.1177/089124194023001004

Nosfinger, R. E. (1991). Everyday Conversations. Newbury Park, CA: Sage.

Odebunmi, A. (2003). Pragmatic Features of English Usage in Hospital Interactions Amongst Medical Practitioners and Patients in South-Western Nigeria. Ph.D. Thesis. Department of English. Obafemi Awolowo University, Ile-Ife. xvii +310 .

Olateju, M. (2004). Turn Allocation Techniques in ESL Chemistry Lessons. In A.L. Oyeleye, (ed.) Language and Discourse in Society. Ibadan: Hope Publications Ltd.

Onadeko, T. (1999). A Discourse Analysis of Conversational Strategies in Magistrate Courts in Nigeria. Ph.D Thesis, Department of English, University of Ilorin, Ilorin. vi +284. 
Peerpapers. (2010). Television Talkshow. [Online] Available: http://www.peerpapers.com/essays/Talk-shows/33497.html? (February 13, 2010)

Sacks, Harvey, Emmanuel A. Schegloff \& Gail Jefferson. (1974). A Simplest Systematics for the Organisation of Turn-Taking for Conversation. Language, 50, 4: 696-735. http://dx.doi.org/10.2307/412243

Schegloff, E. \& Sacks, H. (1973). Opening up closings. Semiotica, 7: 289-327. http://dx.doi.org/10.1515/semi.1973.8.4.289

Shattuc, J.M. (1997). The Talking Cure: TV Talk Shows and Women. London: Routledge.

Thompson, K. (1998). Moral Panics. London: Routledge.

Thornborrow, J. (2001). Has It Ever Happened to You?: Talk Show Stories as Mediated Performance. In A. Tolson, (ed.) Television Talk Shows: Discourse, Performance, Spectacle. Mahwah, NJ: Lawrence Erlbaum, 117-137.

Tolson, A. (2001). Television Talk Show: Discourse, Performance, Spectacle. Mahwah, NJ: Lawrence Erlbaum.

Trepte, S. (2005). Daily Talk as Self-Realization. Media Psychology, Vol. 7(2), May, 165-189. http://dx.doi.org/10.1207/S1532785XMEP0702_3

Wikkipedia. (2009). [Online] Available: http://www.Wikipedia.com (January 23, 2010)

Wilson, K. (2008). Classification of Talkshows. [Online] Available: http://AllFreeEssays.com (February 13, 2010)

Table 1. Frequency of turn distribution strategies in "PG"

\begin{tabular}{|l|l|l|l|l|l|l|l|l|l|l|}
\hline $\begin{array}{l}\text { Turn } \\
\text { distribution } \\
\text { strategies }\end{array}$ & PG1 & $\%$ & PG2 & $\%$ & PG3 & $\%$ & PG4 & $\%$ & $\begin{array}{l}\text { Overall } \\
\text { PG1-PG4 }\end{array}$ & $\%$ \\
\hline CSSN & 48 & 25 & 19 & 12.33 & 15 & 12.09 & 14 & 10.52 & 96 & 15.9 \\
\hline NSSS & 119 & 61.97 & 93 & 60.38 & 94 & 75.80 & 84 & 63.15 & 390 & 64.6 \\
\hline CSC & 25 & 13.02 & 42 & 27.27 & 15 & 12.09 & 35 & 26.31 & 117 & 19.4 \\
\hline Total & 192 & 99.9 & 154 & 99.98 & 124 & 99.98 & 133 & 99.98 & 603 & 99.9 \\
\hline
\end{tabular}

Keys:

CSSN- Current Speaker Selects Next

NSSS- Next Speaker Self-selects

CSC- Current Speaker Continues

Table 2. Frequency of turn distribution strategies in "ND"

\begin{tabular}{|l|l|l|l|l|l|l|l|l|l|l|}
\hline $\begin{array}{l}\text { Turn } \\
\text { distribution } \\
\text { strategies }\end{array}$ & ND1 & $\%$ & ND2 & $\%$ & ND3 & $\%$ & ND4 & $\%$ & $\begin{array}{l}\text { Overall } \\
\text { ND1-ND4 }\end{array}$ & $\%$ \\
\hline CSSN & 23 & 33.82 & 20 & 13.24 & 26 & 32.09 & 28 & 44.44 & 97 & 26.7 \\
\hline NSSS & 31 & 45.58 & 105 & 69.53 & 36 & 44.44 & 15 & 23.80 & 187 & 51.5 \\
\hline CSC & 14 & 20.58 & 26 & 17.21 & 19 & 23.45 & 20 & 31.74 & 79 & 21.7 \\
\hline Total & 68 & 99.98 & 151 & 99.98 & 81 & 99.98 & 63 & 99.98 & 363 & 99.9 \\
\hline
\end{tabular}

Table 3. Frequency of turn distribution strategies in "IO"

\begin{tabular}{|l|l|l|l|l|l|l|l|l|l|l|}
\hline $\begin{array}{l}\text { Turn } \\
\text { distribution } \\
\text { strategies }\end{array}$ & IO1 & $\%$ & IO2 & $\%$ & IO3 & $\%$ & IO4 & $\%$ & $\begin{array}{l}\text { Overall } \\
\text { IO1-IO4 }\end{array}$ & $\%$ \\
\hline CSSN & 8 & 22.8 & 12 & 23.07 & 10 & 35.7 & 15 & 23.43 & 45 & 25.1 \\
\hline NSSS & 23 & 65.7 & 20 & 38.46 & 12 & 42.85 & 48 & 75 & 103 & 57.5 \\
\hline CSC & 4 & 11.42 & 20 & 38.46 & 06 & 21.42 & 1 & 1.56 & 31 & 17.3 \\
\hline Total & 35 & 99.92 & 52 & 99.99 & 28 & 99.97 & 64 & 99.99 & 179 & 99.9 \\
\hline
\end{tabular}

